\title{
REVIEW
}

\section{Hepatitis C Therapy in Renal Patients: Who, How, When?}

\author{
Corinne Isnard Bagnis · Patrice Cacoub
}

Received: February 24, 2016/Published online: July 7, 2016

(C) The Author(s) 2016. This article is published with open access at Springerlink.com

\begin{abstract}
Renal patients are overexposed to hepatitis $\mathrm{C}$ virus (HCV) infection. Hepatitis $\mathrm{C}$ virus infection may induce renal disease, i.e., cryoglobulinemic membrano-proliferative glomerulopathy and non-cryoglobulinemic nephropathy. Hepatitis $\mathrm{C}$ virus impacts general outcomes in chronic kidney disease, dialysis or transplanted patients.
\end{abstract}

Enhanced content To view enhanced content for this article go to http://www.medengine.com/Redeem/ D9D4F0607DE2BBA8.

C. Isnard Bagnis $(\bowtie)$

Department of Nephrology AP-HP, Groupe

Hospitalier Pitié Salpêtrière, 75013 Paris, France

e-mail: corinne.bagnis@psl.aphp.fr

C. Isnard Bagnis

UPMC Univ Paris 06, Paris, France

P. Cacoub

Inflammation-Immunopathology-Biotherapy

Department (DHU i2B), 75005 Paris, France

P. Cacoub

INSERM, UMR_S 959, 75013 Paris, France

P. Cacoub

Department of Internal Medicine and Clinical

Immunology, AP-HP, Groupe Hospitalier

Pitié-Salpêtrière, 75013 Paris, France

P. Cacoub

Sorbonne University, UPMC Univ Paris 06, UMR

7211, Paris, France
Hepatitis $C$ virus infection is now about to be only part of their medical history thanks to new direct acting antiviral drugs exhibiting as much as over $95 \%$ of sustained virological response. All $\mathrm{HCV}$-infected patients potentially can receive the treatment. Control of the virus is associated with better outcomes in all cases, whatever the severity of the hepatic or renal disease. This article focuses on $\mathrm{HCV}$-induced renal diseases, the reciprocal impact of $\mathrm{HCV}$ infection on the renal outcome and renal status in liver disease, use of new direct-acting antiviral drugs with dosage adaptations and the most recent safety data.

Keywords: Chronic kidney disease; Cryoglobulinemia; Dialysis; Direct acting antiviral agents; Hepatitis C; Membranoproliferative glomerulonephritis; Sustained virological response; Transplantation

\section{INTRODUCTION}

Hepatitis C virus (HCV) was discovered 25 years ago [1] and is now about to get a cure. In the meantime, the $\mathrm{C}$ virus has induced tremendous 
morbidity and mortality mainly due to liver complications (cirrhosis, hepatocellular carcinoma). However, many extrahepatic manifestations [2] have been reported for chronic HCV infection with increased related morbidity and mortality, including cardiovascular diseases, type 2 diabetes and insulin resistance, neurocognitive dysfunction, systemic vasculitis, B cell non-Hodgkin lymphoma and chronic kidney disease [3]. Today, some new challenges remain, particularly with regard to specific populations suffering from HCV infection, such as renal patients. Our article focuses on the specificities of screening, monitoring, assessing, treating and following up, in the context of $\mathrm{HCV}$ infection, persons living with chronic kidney disease, end-stage renal failure or a kidney graft.

This article is based on previously conducted studies and does not involve any new studies of human or animal subjects performed by any of the authors.

\section{EPIDEMIOLOGY OF HEPATITIS C VIRUS INFECTION IN RENAL PATIENTS}

Approximately 170 million people are infected with $\mathrm{HCV}$ worldwide and $2.35 \%$ of the total world population [4]. In dialysis patients, the prevalence of $\mathrm{HCV}$ infection has evolved dramatically over the last 10 years. In 2004, the Dialysis Outcomes and Practice Patterns Study (DOPPS) published the largest study analyzing the HCV serological status in 8615 randomly selected hemodialysis patients treated in 308 dialysis facilities (in 8 countries in Europe, HCV USA and Japan) [5]. It showed the HCV antibody prevalence to be $14.7 \%$ when unadjusted and $10.4 \%$ when adjusted for age, gender, race, time with end-stage renal disease, and alcohol or drug abuse in the past 12 months. The updated DOPPS study [6] found a very low prevalence of HCV treatment in dialysis patients as only $1 \%$ of the 4589 patients with available prescription data were receiving $\mathrm{HCV}$ medications. Among a subset of $617 \mathrm{HCV}$ patients known to be on the waiting list for renal transplantation, only $3.7 \%$ were receiving $\mathrm{HCV}$ treatment. In the DOPPS study, the seropositivity for $\mathrm{HCV}$ was associated with black race [odds ratio $(\mathrm{OR})=1.93, P<0.0001$ ], male gender $(\mathrm{OR}=1.18, P=0.01)$, diabetes mellitus $(\mathrm{OR}=1.18, \quad P=0.03)$, a history of gastrointestinal bleeding $(\mathrm{OR}=1.22, P=0.06)$, HBV infection $(\mathrm{OR}=2.56, P<0.0001)$ and prior renal transplant $(\mathrm{OR}=1.34, P=0.01)$. Drug and alcohol abuse, as reported during the 12 months prior to data collection, was also associated with HCV seropositivity ( $\mathrm{OR}=2.44$, $P<0.0001$ and $1.75, P=0.0001$, respectively). At that time, the risk of seroconversion was variable despite infection control measures, and HCV outcomes varied by patient characteristics, country and hemodialysis facility practice patterns. No consensus was available with regard to the need for hemodialysis patient isolation and dedicated dialysis machines to prevent $\mathrm{HCV}$ transmission, in addition to blood-borne precautions [5]. Adjusted $\mathrm{HCV}$ seroconversions/100 patient-years ranged from $1.2(0.7-2.0)$ in the UK to $3.9(2.9-5.2)$ in Italy. In $55.6 \%$ of facilities, the mean seroconversion rate was 0 per 100 patient-years. Seroconversion was mostly associated with the prevalence of $\mathrm{HCV}$ in the facility and with black race [relative risk $(\mathrm{RR})=1.42, P=0.05]$, duration of end-stage renal disease (ESRD) therapy by year [with a $4 \%$ higher risk of seroconversion $(P=0.007)]$ and HIV/AIDS or HBV co-infection $(\mathrm{RR}=3.29$, $P=0.006 \quad$ and $\quad \mathrm{RR}=2.16, \quad P=0.001$, respectively). The authors concluded that this study provided evidence for nosocomial 
transmission of HCV in dialysis facilities but did not demonstrate that isolation of patients infected with $\mathrm{HCV}$ was associated with a decreased risk of HCV seroconversion. The major drawback in this work was the absence of HCV RNA analysis.

A more recent analysis, the DOPPS 5 study (2012-2015) [6], included around 500 facilities and 17,000 patients in 21 countries. It showed that HCV prevalence among hemodialysis patients has declined in recent years in many DOPPS countries but remains higher than in the general population with a prevalence of $9.5 \%$ (in 11,394 patients). We generated the most recent analysis of the prevalence and incidence of HCV and HBV infections in end-stage renal disease patients in France from the REIN registry, a national prospective cohort including 72,948 patients who started dialysis or were preemptively transplanted. We found significantly lower prevalence of both $\mathrm{HBV}$ [1.41\% (95\% CI 1.32-1.49)] and HCV infection [0.84\% (95\% CI 0.78-0.91)] [7].

Transplanted patients are also exposed to HCV infection, mostly through their treatment with dialysis. However, a decrease in the frequency of HCV infection during dialysis has been mirrored by a decreased rate of $\mathrm{HCV}$ infection acquisition following renal transplantation [8].

\section{CLINICAL INVOLVEMENT OF KIDNEY DURING HEPATITIS C VIRUS INFECTION}

\section{Mixed Cryoglobulinemia Vasculitis}

Mixed cryoglobulinemia vasculitis (CryoVas) [9] —a small vessel vasculitis involving mainly the skin, joints, peripheral nerve system and kidneys-is mainly due to HCV infection
(70-80\% of cases). The CryoVas may express mild symptoms (purpura, arthralgia) or more severe life-threatening complications (glomerulonephritis, widespread vasculitis). Renal involvement is an acute or chronic type-I membranoproliferative glomerulonephritis (GNMP) with subendothelial deposits (70-80\% of cases), and it is strongly associated with type II IgM kappa mixed cryoglobulinemia [10]. Patients present with proteinuria, microscopic hematuria, a variable degree of renal insufficiency and new-onset arterial hypertension. Acute nephrotic or nephritic syndrome can also reveal CryoVas renal involvement. Early serum complement component levels (C1q, C4) are very low. Chronic renal insufficiency may develop in $10-20 \%$ of HCV-CryoVas patients. The pathological features are characterized by important monocyte infiltrates with double contours of the basement membrane and large, eosinophilic and amorphous intraluminal thrombi. Indirect immunofluorescence shows intraglomerular subendothelial deposits of IgG, IgM and complement components.

Cryoglobulinemia is confirmed by the detection of protein precipitates in the patient's serum maintained at $4{ }^{\circ} \mathrm{C}$ for at least 7 days, which dissolved when heated at $37^{\circ} \mathrm{C}$. Biological improvement can be assessed by the quantification of cryoglobulinemia and $\mathrm{C} 4$ and CH50 levels [9]. During HCV infection, predictive factors for CryoVas are advanced age, longer duration of infection, type II mixed cryoglobulinemia, higher cryoglobulin serum levels and clonal B cell expansions in both the blood and liver [11]. The overall 5-year survival after the diagnosis of HCV-CryoVas ranges from $90 \%$ to $50 \%$, the latter being reported in case of renal involvement [11-14]. In a retrospective Italian study of 231 
HCV-CryoVas patients [12], 79 of 97 deaths were linked to vasculitis $(46 \%$, of which one-third were due to renal involvement). Life-threatening CryoVas complications are observed in up to $10 \%$ of the patients with almost two-thirds resulting in death [13]. $\mathrm{HCV}$-CryoVas may result in progressive (renal involvement) or acute (pulmonary hemorrhage, gastrointestinal ischemia, cardiac, CNS involvement) life-threatening organ damage. The mortality rate of these manifestations ranges between $20 \%$ and $80 \%$ [14, 15]. Age older than 60 years at diagnosis, the presence of a renal failure, intestinal ischemia, pulmonary hemorrhage, high cryocrit levels and type II mixed cryoglobulinemia are associated with severe prognosis [13].

In HCV-infected patients, many factors have been described to predispose patients to a CryoVas. Interaction between the virus and immune cells directly modulates B- and T-cell function resulting in expansion of B-cell production of IgM with RF activity [16]. The $\mathrm{CD}^{+}{ }^{+} \mathrm{CD} 25^{+} \mathrm{FoxP}^{+}$regulatory $\mathrm{T}$ cell number is significantly reduced $[17,18]$, possibly leading to the expansion of peripheral auto-reactive B-cells. HLA-DR11 is associated with HCV-CryoVas, whereas HLA-DR7 appears to protect patients from the production of type II mixed cryoglobulinemia [19]. In a large multicenter study significant associations were identified on chromosome 6, a SNP located within an intronic region of NOTCH4 $\left(p=6.2 \times 10^{-9}\right)$, and another was found in between HLA-DRB1 and HLA-DQA1 $\left(p=1.2 \times 10^{-7}\right) \quad$ [20]. A higher percentage of a particular allele of the promoter of the B-cell activating factor and different expression patterns on circulating lymphocytes of microRNAs known to be involved in lymphoproliferative and/or autoimmune disorders have been shown [21, 22]. Specific virological factors have never been identified.

\section{Non-Cryoglobulinemic Renal Involvement in HCV-Infected Patients}

Other glomerular diseases in both native [23] and transplanted kidneys [24] have been more rarely reported. In a large case-control study in US hospitalized male veterans [25], there was a greater proportion of MPGN among patients with $\mathrm{HCV}(0.36 \%$ vs. $0.05 \%, p<0.0001)$, but not of membranous glomerulopathy. HCV-infected patients showed a 40\% higher prevalence of renal insufficiency compared with non-HCV-infected people [26]. Other large surveys also suggested an impact of $\mathrm{HCV}$ infection on the prevalence and incidence of kidney disease in the general population [26-30]. The HCV seropositive status was associated with low GFR (OR up to 2.80) and proteinuria (OR 1.14-1.99), independently of diabetes mellitus, arterial hypertension, obesity and dyslipidemia [31]. In a recent population-based cohort among 2,267,270 Taiwanese residents diagnosed with diabetes mellitus [32], the cumulative incidences of ESRD at 8 years in the HCV-treated, $\mathrm{HCV}$-untreated and uninfected cohorts were $1.1 \%, 9.3 \%$ and $3.3 \%$, respectively. As compared with the untreated cohort, $\mathrm{HCV}$ treatment was associated with an HR of 0.16 (0.07-0.33\%) for ESRD. Recent information has also accumulated on the association between $\mathrm{HCV}$ and glomerular disease in the liver $[33,34]$ or kidney/liver [35] transplanted population. The natural history of these HCV-associated nephropathies is characterized by remission and relapsing phases. Finally, HIV-HCV coinfection was also linked with a significant increase in the risk of HIV-related kidney disease [36, 37].

The Kidney Disease Improving Global Outcomes (KDIGO) group recommends that all patients with chronic kidney disease should be tested for HCV [38]. The KDIGO also 
recommended that patients with acute flares of CryoVas and MPGN be treated with IFN-based HCV treatment. No doubt with recent advances in $\mathrm{HCV}$ treatment and direct-acting agents (DAAs) on the market such recommendations should be updated, i.e., should recommend IFN-free $\mathrm{HCV}$ treatment for patients with CryoVas and MPGN. In HCV-CryoVas patients with kidney involvement, the addition of rituximab to antivirals showed greater renal response rates than antivirals alone [39, 40]. However, considering the great and very rapid virological efficacy of DAAs, the remaining place of rituximab in HCV-MPGN needs to be further studied.

\section{Impact of CKD on Hepatitis C Outcomes}

Several studies have demonstrated that dialysis is associated with an increased risk of all-cause and liver-related mortality [41-43]. In this population, cardiovascular disease remains the first cause for death. CKD always impacts the treatment of chronic diseases negatively because of the poorer drug tolerance, higher prevalence of side effects and complexity of drug dosage adaptation. Hepatitis $\mathrm{C}$ treatment has long been offered through peginterferon alpha associated with ribavirin with very poor tolerance and a high prevalence of anemia and depressive syndrome leading to anticipated resuming of therapy [42]. Of note, HCV-Cryovas patients who present a GNMP showed a lower response rate to IFN-based treatment, whereas they showed a higher benefit of rituximab.

In transplanted patients, immunosuppression has been associated with an increase of serum HCV-RNA levels [43], and contradictory results emerged from the histological data on hepatic fibrosis after kidney transplantation. Some observations reported dramatically bad outcomes after kidney transplantation with fibrosing cholestatic hepatitis [44]. Survival after transplantation was reported to be impacted negatively by a predisposition to progressive liver disease [8]. Besides, onset of new diabetes is significantly increased after transplantation potentially leading to metabolic complications.

\section{TREATMENT OF HEPATITIS C INFECTION}

\section{In Patients with HCV-CryoVas}

The CryoVas manifestations respond dramatically to HCV cure after antiviral therapy with pegylated interferon (IFN) plus ribavirin [45-48]. In case of persistent mixed cryoglobulinemia after HCV cure, when relapse of vasculitis also occurs, a different condition should be considered, especially B-cell lymphoma [49]. A recent open-label French prospective study [50] showed the good efficacy of a combination therapy with Peg-IFN/ribavirin plus a NS3/4A protease inhibitor (boceprevir or telaprevir) in patients with HCV-CryoVas. At week 24 post-treatment, two-thirds of patients were complete clinical responders, and their HCV was cured. However, serious adverse events occurred in half of the patients. In a prospective Italian study [51], HCV-CryoVas patients treated with Peg-IFN/ ribavirin/boceprevir for 48 weeks showed a dramatic reduction in the cryocrit values and improvement of CryoVas symptoms. Other DAAs such as the NS5B inhibitor sofosbuvir, NS3/4A inhibitor simeprevir and NS5A inhibitor daclatasvir have been more recently licensed. These agents facilitate the use of shortened courses of combination IFN-free therapy, showing SVR rates $>95 \%$ and few toxicities. International guidelines [52] recommend that 
treatment should be scheduled, not deferred, for patients with clinically significant extra-hepatic manifestations, like CryoVas. A very recent open-label cohort study enrolled 24 patients with HCV-CryoVas who received an all-oral IFN-free regimen with sofosbuvir (400 mg/day) and ribavirin (200-1400 mg/day) for 24 weeks [53]. At week 12 post-treatment, $85 \%$ of patients were in complete remission for the CryoVas and $74 \%$ had an SVR, with a low rate of serious adverse events. The cryoglobulin level decreased from 0.35 to $0.15 \mathrm{~g} / \mathrm{l}$, while the C4 serum level increased from 0.10 to $0.17 \mathrm{~g} / \mathrm{l}$. Among patients with kidney involvement, renal function improved in four out of five, proteinuria decreased from $1.09(0.6-2.4)$ to $0.17 \quad(0.07-0.25) \quad \mathrm{g} /$ day and hematuria disappeared in all cases. Another study reported $12 \mathrm{HCV}$-Cryovas patients treated with sofosbuvir-based regimens [54]. Median baseline serum creatinine was $0.97 \mathrm{mg} / \mathrm{dl}$ (range $0.7-2.47 \mathrm{mg} / \mathrm{dl}$ ). Four patients received rituximab concurrently with DAA therapy. The SVR at 12 weeks post-treatment was $83 \%$. Patients with glomerulonephritis who achieved SVR12 experienced an improvement in serum creatinine and reduction in proteinuria. Serious adverse events were infrequent (17\%). The historical cohort in this study treated with pegylated-IFN and ribavirin experienced a 10\% SVR12 rate and 50\% experienced premature discontinuation due to adverse events.

Rituximab targets B-cells, which are responsible for cryoglobulin production and finally vasculitic lesions [55-59]. In a randomized controlled trial of HCV-CryoVas patients, rituximab showed better efficacy than immunosuppressive treatments or plasmapheresis [60]. Similar results have been reported in a placebo-controlled trial [61]. The use of rituximab was shown to be safe in HCV patients, in contrast with what was observed in HBV-infected patients [62, 63]. Two controlled clinical trials showed that rituximab plus Peg-IFN/ribavirin compared to Peg-IFN/ ribavirin led to a shorter time to clinical remission, better renal response rate and higher rates of cryoglobulin clearance $[39,40]$. However, there are no data indicating the exact place of rituximab with the use of DAAs, particularly if an IFN-free DAA combination is used before or at the same time as rituximab therapy.

Low-dose corticosteroids may help to control arthralgia but do not succeed in case of major organ involvement. Other immunosuppressants should be given in case of refractory HCV-CryoVas associated with underlying B-cell lymphoma [64].

\section{In CKD Patients and ESRD Patients (Including Dialysis and Transplantation): Use and Monitoring of DAAs}

In the past decade, peginterferon and ribavirin were considered the mainstay of hepatitis $C$ virus treatment in CKD patients despite a high prevalence of side effects and poor clinical and biological tolerance. New DAAs offer dramatically improved efficacy in the general population.

Hepatitis C treatment may be discussed at any time of the follow-up when the glomerular filtration rate decreases during dialysis treatment, before and after renal transplantation [65].

It is a matter of debate whether hepC therapy should occur before or after transplantation [65]. Drug-drug interactions will definitively make monitoring more complex after transplantation since the impact of DAAs on tubular transports and cytochrome metabolisms will dramatically impact the pharmacokinetic 
properties of immunosuppressive drugs [66]. New strategies will now emerge with regard to $\mathrm{HCV}$ treatment before or after renal transplantation depending also on the availability of a living donor or not. In case of a living donor, it has been proposed that DDA's treatment should occur before transplantation in order to obtain SVR12. When there is no living donor available, some centers (with a signed consent from the patient) will offer an HCV-positive graft to the patient and begin DAA treatment after transplantation, therefore reducing waiting times significantly [65]. DAA's availability will definitely further change the organ allocation criteria.

The information on the efficacy and safety of DAAs for HCV therapy in patients with renal failure is limited, but DAAs have begun to show their indications in stage 4 and 5 CKD patients. One of the available combinations of DAAs approved for patients with $15<\mathrm{GFR}<30 \mathrm{ml} /$ $\mathrm{min}$ is the paritaprevir/ritonavir plus ombitasvir combination [67]. In this study, HCV genotype 1 treatment-naïve patients (without cirrhosis) were included in an open-label treatment study if they had stage 4 or $5 \mathrm{CKD}$. Twenty patients received DAAs for 12 weeks in two groups ( $N=7$ for genotype $1 \mathrm{a}$ receiving the paritaprevir/ritonavir plus ombitasvir combination and $N=13$ for genotype $1 \mathrm{~b}$ receiving the paritaprevir/ritonavir plus ombitasvir plus ribavirin combination). Two patients failed to achieve SVR12, and the overall tolerance of the treatment was satisfying. The choice of the appropriated drug must take into account the viral genotype as well as the tolerance in patients with decreased GFR. It is noteworthy, for example, that the paritaprevir/ritonavir/ombitasvir/dasabuvir combination is approved for CKD only in genotype 1 patients and that the paritaprevir/ ritonavir/ombitasvir combination is only effective for HCV-4.

The other combination showing good efficacy and tolerability in CKD settings is described in the C-SURFER study [68]. In this multicenter phase III all oral combination of grazoprevir $100 \mathrm{mg} /$ day (HCV NS3/4A inhibitor) and elbasvir $50 \mathrm{mg} /$ day (HCV NS5A inhibitor), 99.1\% SVR12 was obtained in HCV genotype 1 patients with stage 4 and 5 CKD and compensated cirrhosis. Treatment was generally well tolerated. Less than $1 \%$ of grazoprevir and elbasvir was renally excreted [69]. Patients treated with hemodialysis were included in this study, whereas no data have been published on peritoneal dialysis patients. The grazoprevir/elbasvir combination, with or without ribavirin, was recently approved by the FDA for the treatment of chronic HCV genotype 1 and 4 infections in adult patients and was granted breakthrough therapy designation for the treatment of chronic HCV genotype 1 infection in patients with end-stage renal disease on hemodialysis and for the treatment of chronic HCV genotype 4 infection $[69,70]$.

Other DAA combinations may be used in CKD patients with well-preserved renal function, such as sofosbuvir (NS5B polymerase inhibitor) together with simeprevir (NS3/4A protease inhibitor), daclatasvir or ledipasvir (both NS5A inhibitors) with expected efficacy comparable to that of the general population. However, decreased renal function was observed with sofosbuvir in patients with GFR below $45 \mathrm{ml} / \mathrm{min} / 1.73 \mathrm{~m}^{2}$ [70]. An active metabolite of sofosbuvir is actively renally secreted, and therefore overexposure may be observed in CKD patients. Sofosbuvir is used at a 400-mg daily dosage in patients with GFR above $30 \mathrm{ml} / \mathrm{min} / 1.73 \mathrm{~m}^{2}$. However, the 


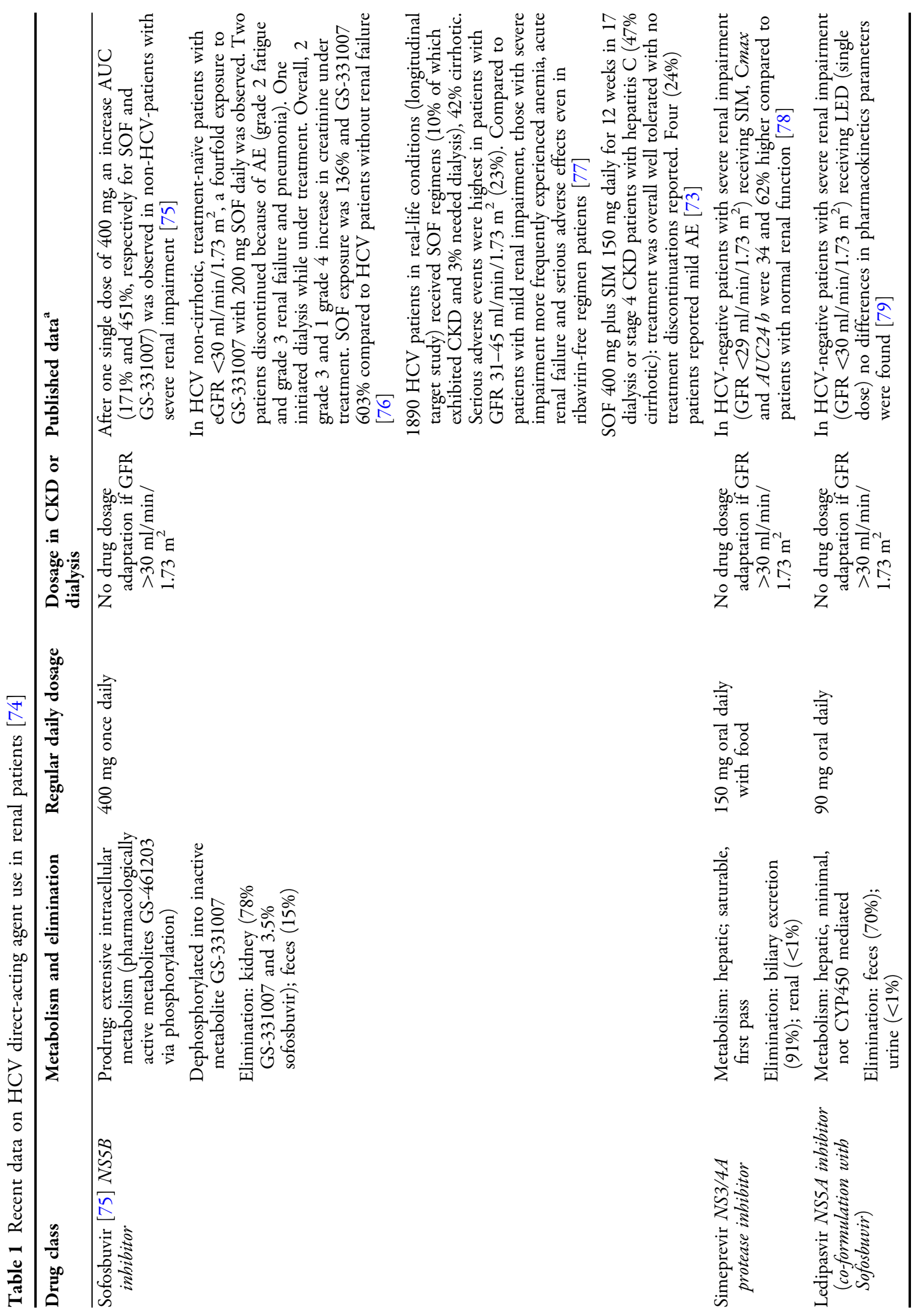




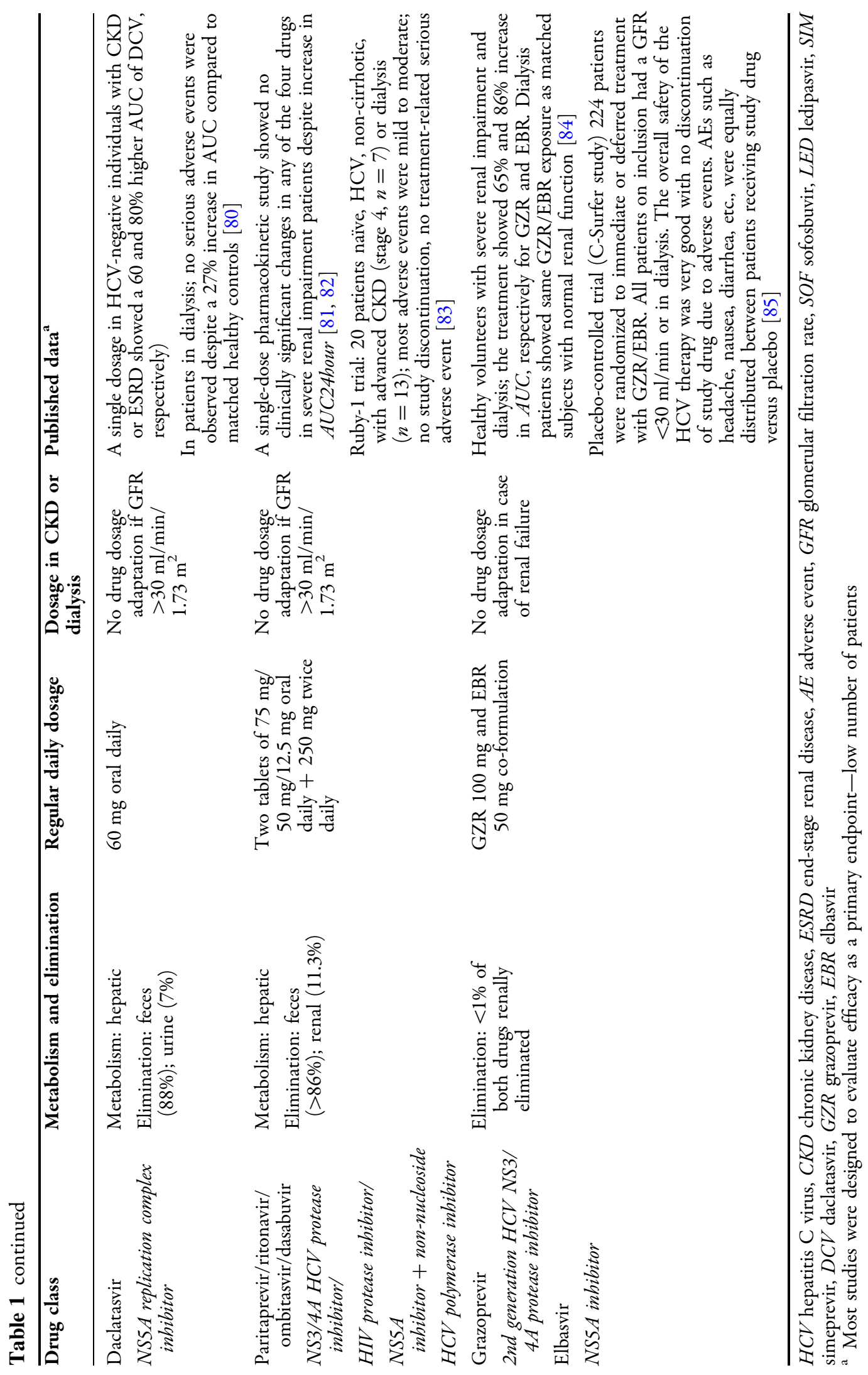


Table 2 Recent published guidelines for use of DAAs in CKD patients with comments from the latest publications

\section{AASLD 2015}

For patients with mild to moderate renal impairment (GFR $>30-80 \mathrm{ml} / \mathrm{min}$ ), no dosage adjustment is required when using sofosbuvir, simeprevir, a fixed-dose combination of ledipasvir $(90 \mathrm{mg}) /$ sofosbuvir $(400 \mathrm{mg})$ or fixed-dose combination of paritaprevir $(150 \mathrm{mg}) /$ ritonavir $(100 \mathrm{mg}) / \mathrm{ombitasvir}(25 \mathrm{mg})$ plus twice-daily dosed dasabuvir $(250 \mathrm{mg})$ to treat or retreat $\mathrm{HCV}$ infection in patients with appropriate genotypes (I-A)

For treatment-naive patients with HCV genotype 1 without cirrhosis with GFR $<30 \mathrm{ml} / \mathrm{min}$, treatment with the daily fixed-dose combination of paritaprevir $(150 \mathrm{mg}) /$ ritonavir $(100 \mathrm{mg}) / \mathrm{ombitasvir}(25 \mathrm{mg})$ plus twice-daily dosed dasabuvir $(250 \mathrm{mg}$ ) with (1a) or without (1b) RBV (200 mg) once daily is recommended

RBV should only be given if the baseline hemoglobin level is greater than $10 \mathrm{~g} / \mathrm{dl}$

For patients with moderate renal impairment (eGFR 30-50 ml/min), initial RBV dosing should be 200 or $400 \mathrm{mg}$ alternating every other day

For patients with severe renal impairment or who are on hemodialysis (eGFR $<30 \mathrm{ml} / \mathrm{min}$ ), initial RBV dosing should be $200 \mathrm{mg}$ daily (II-B)

\section{EASL 2015 Hepatitis C guidelines in hemodialysis patients}

Simeprevir, daclatasvir and the combination of ritonavir-boosted paritaprevir, ombitasvir and dasabuvir are cleared by hepatic metabolism and can be used in patients with severe renal disease (A1)

Sofosbuvir should not be administered to patients with an eGFR $<30 \mathrm{ml} / \mathrm{min} / 1.73 \mathrm{~m}^{2}$ or with end-stage renal disease until more data are available (B2)

The need for dose adjustments for the approved HCV DAAs in patients on dialysis is unknown. No safety dosing and efficacy data are available in this population

These drugs should thus be used with extreme caution in patients with severe renal disease and only in extreme life-threatening situations for patients on dialysis (B1)

Hemodialysis patients, particularly those who are suitable candidates for renal transplantation, should be considered for antiviral therapy $(\mathrm{B} 1)$

Hemodialysis patients should receive an IFN-free, if possible ribavirin-free regimen for 12 weeks in patients without cirrhosis, for 24 weeks in patients with cirrhosis (B1)

authors tested a full dose or half dose of sofosbuvir in stage 4 or 5 patients (on dialysis or not) despite the exclusive renal elimination pathway [71, 72]. They showed no discontinuation due to side effects and no significant adverse events in small groups of patients. These results need to be confirmed in larger populations of CKD patients.

Despite better efficacy and good tolerance in CKD patients, DAAs may not be available, and depending on the local conditions, older therapies such as PEG-interferons could still be offered with much less chance of SVR but at a lesser cost.

Other oral DDA combinations may be used in renal patients based on their hepatic metabolism. The risk of renal pharmacokinetic modifications in cirrhotic patients is high, and DAAs with hepatic metabolism in this context may not guarantee renal safety.

The HCV lifecycle can be blocked at many steps. HCV DAAs on the market or in clinical 
development include NS3-4A protease inhibitors, nucleotide analog inhibitors of HCV RNA-dependent RNA polymerase (RdRp), non-nucleoside inhibitors of HCV RdRp and inhibitors of the non-structural 5A (NS5A) protein. These drugs differ in their activity against the different HCV genotypes and their barrier to resistance. They also differ in terms of the hepatic and renal metabolism. Some good reviews offer tables that detail drug dosage adaptations in renal failure [73]. In Table 1, we give a recent update of DAA use in renal patients. However, many other studies are ongoing that will allow a better knowledge of their safety in real-life conditions. New guidelines have been released with regard to hepatitis $\mathrm{C}$ treatment from both European and American societies (Table 2).

\section{Unsolved Questions}

In the context of HCV-CryoVas, considering the very rapid and potent virological efficacy of the new DAA combination (i.e., SVR $>95 \%$, viremia negative in $<4$ weeks) and the well-demonstrated correlation between SVR and clinical response, the exact place of rituximab, plasmapheresis or other immunosuppressive drugs remains to be defined.

In the context of a chronic renal insufficiency in $\mathrm{HCV}$-infected patients not related to HCV-CryoVas, the role and impact of new DAA combinations on kidney function should be analyzed in large prospective studies with mid- and long-term follow-up, including GFR, proteinuria and hematuria.

\section{CONCLUSION}

New DAAs make the future of patients living with hepatitis $\mathrm{C}$ very exciting with a promise of a cure from the viral infection. Major challenges for the clinicians remain optimal use of the new drugs and further monitoring of chronic kidney disease patients living with sustained viral response to ensure long-term renal protection.

\section{ACKNOWLEDGMENTS}

No funding or sponsorship was received for this study or publication of this article. All named authors meet the International Committee of Medical Journal Editors (ICMJE) criteria for authorship for this manuscript, take responsibility for the integrity of the work as a whole and have given final approval for the version to be published.

Disclosures. C. Isnard Bagnis has received honoraria, advisory board and speakers' fees: Gilead, AbbVie and MSD. P. Cacoub has received consultancies, honoraria, advisory board and speakers' fees: Abbvie, Astra Zeneca, Bayer, Boehringer Ingelheim, Gilead, Glaxo Smith Kline, Janssen, Merck Sharp Dohme, Pfizer, Roche, Servier, Vifor.

Compliance with Ethics Guidelines. This article is based on previously conducted studies and does not involve any new studies of human or animal subjects performed by any of the authors.

Open Access. This article is distributed under the terms of the Creative Commons Attribution-NonCommercial 4.0 International License (http://creativecommons.org/licenses/ by-nc/4.0/), which permits any noncommercial use, distribution, and reproduction in any medium, provided you give appropriate credit to the original author(s) and the source, provide 
a link to the Creative Commons license, and indicate if changes were made.

\section{REFERENCES}

1. Choo QL, Kuo G, Weiner AJ, Overby LR, Bradley DW, Houghton M. Isolation of a cDNA clone derived from a blood-borne non-A, non-B viral hepatitis genome. Science. 1989;244:359-62.

2. Cacoub P, Poynard T, Ghillani P, et al. Extrahepatic manifestations of chronic hepatitis C. MULTIVIRC Group. Multidepartment virus C. Arthritis Rheum. 1999;42(10):2204-12.

3. Cacoub P, Gragnani L, Commarmond C, Zignego AL. Extrahepatic manifestations of chronic hepatitis C virus infection. Dig Liver Dis. 2014;46 Suppl 5:S165-73.

4. Lavanchy D. Evolving epidemiology of hepatitis C virus. Clin Microbiol Infect. 2011;17(2):107-15.

5. Fissell RB, Bragg-Gresham JL, Woods JD, Jadoul M, Gillespie B, Hedderwick SA, et al. Patterns of hepatitis $\mathrm{C}$ prevalence and seroconversion in hemodialysis units from three continents: the DOPPS. Kidney Int. 2004;65(6):2335-42.

6. Goodkin DA, Bieber B, Gillespie B, Robinson BM, Jadoul M. Hepatitis C infection is very rarely treated among hemodialysis patients. Am J Nephrol. 2013;38:405-12.

7. Isnard Bagnis C, Layese R, Divard G, et al and ANRS CO12 CirVir prospective group. Viral suppression is not a risk factor for CKD in viral cirrhosis (ANRS CO12 CIRVIR Prospective cohort). Poster and e poster EASL 2016, Barcelona, ILC2016-RS-1182.

8. Sawinski D, Bloom RD. Novel hepatitis C treatment and the impact on kidney transplantation. Transplantation. 2015;99(12):2458-66. doi:10. 1097/TP.0000000000000847.

9. Cacoub P, Comarmond C, Domont C, Savey L, Saadoun D. Cryoglobulinemia vasculitis. Am J Med. 2015;128(9):950-5.

10. Terrier B, Cacoub P. Renal involvement in HCV-related vasculitis. Clin Res Hepatol Gastroenterol. 2013;37(4):334-9.

11. Terrier $B$, Semoun $O$, Saadoun $D$, Sène $D$, Resche-Rigon M, Cacoub P. Prognostic factors in patients with hepatitis $\mathrm{C}$ virus infection and systemic vasculitis. Arthritis Rheum. 2011;63(6):1748-57.
12. Ferri C, Sebastiani M, Giuggioli D, et al. Mixed cryoglobulinemia: demographic, clinical, and serologic features and survival in 231 patients. Semin Arthritis Rheum. 2004;33(6):355-74.

13. Ramos-Casals $\mathrm{M}$, Robles A, Brito-Zerón $\mathrm{P}$, et al. Life-threatening cryoglobulinemia: clinical and immunological characterization of 29 cases. Semin Arthritis Rheum. 2006;36(3):189-96.

14. Retamozo S, Díaz-Lagares C, Bosch $\mathrm{X}$, et al. Life-threatening cryoglobulinemic patients with hepatitis C: clinical description and outcome of 279 patients. Medicine (Baltimore). 2013;92(5):273-284.

15. Terrier B, Karras A, Cluzel P, et al. Presentation and prognosis of cardiac involvement in hepatitis $\mathrm{C}$ virus-related vasculitis. Am J Cardiol. 2013;111(2):265-72.

16. Saadoun D, Bieche I, Maisonobe $\mathrm{T}$, et al. Involvement of chemokines and type 1 cytokines in the pathogenesis of hepatitis $C$ virus-associated mixed cryoglobulinemia vasculitis neuropathy. Arthritis Rheum. 2005;52(9):2917-25.

17. Boyer O, Saadoun D, Abriol J, et al. CD4+ CD25+ regulatory T-cell deficiency in patients with hepatitis C-mixed cryoglobulinemia vasculitis. Blood. 2004;103(9):3428-30.

18. Saadoun D, Rosenzwajg M, Joly F, et al. Regulatory T-cell responses to low-dose interleukin-2 in HCV-induced vasculitis. $\mathrm{N}$ Engl J Med. 2011;365(22):2067-77.

19. Cacoub P, Renou C, Kerr G, et al. Influence of HLA-DR phenotype on the risk of hepatitis $\mathrm{C}$ virus-associated mixed cryoglobulinemia. Arthritis Rheum. 2001;44(9):2118-24.

20. Zignego AL, Wojcik GL, Cacoub $\mathrm{P}$, et al. Genome-wide association study of hepatitis C virus- and cryoglobulin-related vasculitis. Genes Immun. 2014;15(7):500-5. doi:10.1038/gene.2014. 41.

21. Gragnani L, Piluso A, Giannini C, et al. Genetic determinants in hepatitis $C$ virus-associated mixed cryoglobulinemia: role of polymorphic variants of BAFF promoter and Fc $\gamma$ receptors. Arthritis Rheum. 2011;63(5):1446-51.

22. Fognani E, Giannini C, Piluso A, et al. Role of microRNA profile modifications in hepatitis $\mathrm{C}$ virus-related mixed cryoglobulinemia. PLoS One. 2013;8(5):e62965.

23. Fabrizi F, Poordad FF, Martin P. Hepatitis C infection and the patient with end-stage renal disease. Hepatology. 2002;36(1):3-10. 
24. Roth D, Cirocco R, Zucker $\mathrm{K}$, et al. De novo membranoproliferative glomerulonephritis in hepatitis $C$ virus-infected renal allograft recipients. Transplantation. 1995;59(12):1676-82.

25. El-Serag HB, Hampel H, Yeh C, Rabeneck L. Extrahepatic manifestations of hepatitis $\mathrm{C}$ among United States male veterans. Hepatology. 2002;36(6):1439-45.

26. Dalrymple LS, Koepsell T, Sampson J, et al. Hepatitis $C$ virus infection and the prevalence of renal insufficiency. Clin J Am Soc Nephrol. 2007;2(4):715-21.

27. Asrani SK, Buchanan P, Pinsky B, Rey LR, Schnitzler M, Kanwal F. Lack of association between hepatitis $\mathrm{C}$ infection and chronic kidney disease. Clin Gastroenterol Hepatol. 2010;8(1):79-84.

28. Butt AA, Wang X, Fried LF. HCV infection and the incidence of CKD. Am J Kidney Dis. 2011;57(3):396-402.

29. Lee J-J, Lin M-Y, Yang Y-H, Lu S-N, Chen H-C, Hwang S-J. Association of hepatitis $\mathrm{C}$ and $\mathrm{B}$ virus infection with CKD in an endemic area in Taiwan: a cross-sectional study. Am J Kidney Dis. 2010;56(1):23-31.

30. Tsui JI, Vittinghoff E, Shlipak MG, O'Hare AM. Relationship between hepatitis $\mathrm{C}$ and chronic kidney disease: results from the Third National Health and Nutrition Examination Survey. J Am Soc Nephrol. 2006;17(4):1168-74.

31. Liangpunsakul S, Chalasani N. Relationship between hepatitis $\mathrm{C}$ and microalbuminuria: results from the NHANES III. Kidney Int. 2005;67(1):285-90.

32. Hsu Y-C, Lin J-T, Ho HJ, Kao Y-H, Huang Y-T, Hsiao $\mathrm{N}-\mathrm{W}$, et al. Antiviral treatment for hepatitis $\mathrm{C}$ virus infection is associated with improved renal and cardiovascular outcomes in diabetic patients. Hepatol Baltim Md. 2014;59(4):1293-302.

33. Davis CL, Gretch DR, Perkins JD, et al. Hepatitis $\mathrm{C}$-associated glomerular disease in liver transplant recipients. Liver Transpl Surg. 1995;1(3):166-75.

34. Sikaneta T, Williams WW, Chung RT, Cosimi AB, Pascual AM. Remission of hepatitis $C$ virus-associated cryoglobulinemic glomerulonephritis with interferon alfa-2b and ribavirin combination therapy after liver transplantation. 2002;74(12):1767-8.

35. Montalbano M, Pasulo L, Sonzogni A, Remuzzi G, Colledan M, Strazzabosco M. Treatment with pegylated interferon and ribavirin for hepatitis $\mathrm{C}$ virus-associated severe cryoglobulinemia in a liver/ kidney transplant recipient. J Clin Gastroenterol. 2007;41(2):216-20.

36. Izzedine $\mathrm{H}$, Sene D, Cacoub $\mathrm{P}$, et al. Kidney diseases in HIV/HCV-co-infected patients. AIDS. 2009;23(10):1219-26.

37. Wyatt CM, Malvestutto C, Coca SG, Klotman PE, Parikh CR. The impact of hepatitis $C$ virus coinfection on HIV-related kidney disease: a systematic review and meta-analysis. AIDS. 2008;22(14):1799-807.

38. Kidney Disease: Improving Global Outcomes (KDIGO). KDIGO clinical practice guidelines for the prevention, diagnosis, evaluation, and treatment of hepatitis $\mathrm{C}$ in chronic kidney disease. Kidney Int Suppl. 2008;109:S1-99.

39. Dammacco F, Tucci FA, Lauletta G, et al. Pegylated interferon-alpha, ribavirin, and rituximab combined therapy of hepatitis $\mathrm{C}$ virus-related mixed cryoglobulinemia: a long-term study. Blood. 2010;116(3):343-53.

40. Saadoun D, Resche Rigon M, Sene D, et al. Rituximab plus Peg-interferon-alpha/ribavirin compared with Peg-interferon-alpha/ribavirin in hepatitis C-related mixed cryoglobulinemia. Blood. 2010;116(3):326-34.

41. Liu $\mathrm{CH}, \mathrm{Kao} \mathrm{JH}$. Treatment of hepatitis $\mathrm{C}$ virus infection in patients with end-stage renal disease. J Gastroenterol Hepatol. 2011;26(2):228-39.

42. Bunchorntavakul C, Maneerattanaporn M, Chavalitdhamrong D. Management of patients with hepatitis $\mathrm{C}$ infection and renal disease. World J Hepatol. 2015;7:213-25.

43. Izopet J, Rostaing L, Sandres K, Cisterne JM, Pasquier C, Rumeau JL, et al. Longitudinal analysis of hepatitis $\mathrm{C}$ virus replication and liver fibrosis progression in renal transplant recipients. J Infect Dis. 2000;181:852-8.

44. Delladetsima JK, Boletis JN, Makris F, Psichogiou M, Kostakis A, Hatzakis A. Fibrosing cholestatic hepatitis in renal transplant recipients with hepatitis C virus infection. Liver Transpl Surg. 1999;5:294-300.

45. Ferri C, Marzo E, Longombardo G, et al. Interferon-alpha in mixed cryoglobulinemia patients: a randomized, crossover-controlled trial. Blood. 1993;81(5):1132-6.

46. Misiani R, Bellavita $\mathrm{P}$, Fenili $\mathrm{D}$, et al. Interferon alfa-2a therapy in cryoglobulinemia associated with hepatitis $\mathrm{C}$ virus. $\mathrm{N}$ Engl J Med. 1994;330(11):751-6. 
47. Fabrizi F, Plaisier E, Saadoun D, Martin P, Messa P, Cacoub P. Hepatitis $C$ virus infection, mixed cryoglobulinemia, and kidney disease. Am J Kidney Dis. 2013;61(4):623-37.

48. Saadoun D, Resche-Rigon M, Thibault V, Piette J-C, Cacoub P. Antiviral therapy for hepatitis C virus-associated mixed cryoglobulinemia vasculitis: a long-term follow up study. Arthritis Rheum. 2006;54(11):3696-706.

49. Landau D-A, Saadoun D, Halfon P, et al. Relapse of hepatitis $C$ virus-associated mixed cryoglobulinemia vasculitis in patients with sustained viral response. Arthritis Rheum. 2008;58(2):604-11.

50. Saadoun D, Resche Rigon M, Pol S, et al. Peg-IFNaRibavirin/Protease inhibitor combination in severe hepatitis $\mathrm{C}$ virus associated mixed cryoglobulinemia vasculitis. J Hepatol. 2015;62(1):24-30. doi:10.1016/j.jhep.2014.08.015.

51. Gragnani L, Fabbrizzi A, Triboli E, et al. Triple antiviral therapy in hepatitis $C$ virus infection with or without mixed cryoglobulinaemia: a prospective, controlled pilot study. Dig Liver Dis. 2014;46(9):833-7.

52. European Association for Study of Liver. EASL Clinical Practice Guidelines: management of hepatitis C virus infection. J Hepatol. 2014;60(2):392-420.

53. Saadoun D, Thibault V, Pialoux G, Elkrief L, Mallet $\mathrm{M}$, Musset $\mathrm{L}$, et el. All oral therapy (Sofosbuvir-Ribavirin) combination in severe HCV-mixed cryoglobulinemia vasculitis, The VASCULVADIC study. J Hepatol. 2015;62:S640.

54. Sise ME, Bloom AK, Wisocky J, et al. Treatment of hepatitis $\mathrm{C}$ Virus-associated mixed cryoglobulinemia with sofosbuvir-based direct-acting antiviral agents. Hepatology. 2016;63(2). doi:10.1002/hep.28297.

55. Roccatello D, Baldovino S, Rossi D, et al. Long-term effects of anti-CD20 monoclonal antibody treatment of cryoglobulinaemic glomerulonephritis. Nephrol Dial Transpl. 2004;19(12):3054-61.

56. Saadoun D, Resche-Rigon M, Sene D, Perard L, Karras A, Cacoub P. Rituximab combined with Peg-interferon-ribavirin in refractory hepatitis C virus-associated cryoglobulinaemia vasculitis. Ann Rheum Dis. 2008;67(10):1431-6.

57. Sansonno D, De Re V, Lauletta G, Tucci FA, Boiocchi M, Dammacco F. Monoclonal antibody treatment of mixed cryoglobulinemia resistant to interferon alpha with an anti-CD20. Blood. 2003;101(10):3818-26.

58. Zaja F, De Vita S, Mazzaro C, et al. Efficacy and safety of rituximab in type II mixed cryoglobulinemia. Blood. 2003;101(10):3827-34.

59. Cacoub P, Delluc A, Saadoun D, Landau DA, Sene D. Anti-CD20 monoclonal antibody (rituximab) treatment for cryoglobulinemic vasculitis: where do we stand? Ann Rheum Dis. 2008;67(3):283-7.

60. De Vita S, Quartuccio L, Isola $\mathrm{M}$, et al. A randomized controlled trial of rituximab for the treatment of severe cryoglobulinemic vasculitis. Arthritis Rheum. 2012;64(3):843-53.

61. Sneller $\mathrm{MC}, \mathrm{Hu} \mathrm{Z}$, Langford CA. A randomized controlled trial of rituximab following failure of antiviral therapy for hepatitis $\mathrm{C}$ virus-associated cryoglobulinemic vasculitis. Arthritis Rheum. 2012;64(3):835-42.

62. Droz N, Gilardin L, Cacoub P, et al. Kinetic profiles and management of hepatitis $\mathrm{B}$ virus reactivation in patients with immune-mediated inflammatory diseases. Arthritis Care Res. 2013;65(9):1504-14.

63. Petrarca A, Rigacci L, Caini P, et al. Safety and efficacy of rituximab in patients with hepatitis $C$ virus-related mixed cryoglobulinemia and severe liver disease. Blood. 2010;116(3):335-42.

64. Saadoun D, Pineton de Chambrun M, Hermine O, et al. Using rituximab plus fludarabine and cyclophosphamide as a treatment for refractory mixed cryoglobulinemia associated with lymphoma. Arthritis Care Res. 2013;65(4):643-7.

65. Ladino M, Pedraza F, Roth D. Hepatitis C virus infection in chronic kidney disease. J Am Soc Nephrol. 2016. pii: ASN.2016010030.

66. Bhamidimarri KR, Martin P, Levy $P$, et al. Renal function decline is frequent in patients underegoing hepatitis $C$ treatment post kidney transplant. J Hepatol. 2016;64:S784.

67. Pockros PJ, Reddy KR, Mantry PS, Cohen E, Bennett $M$, et al. Efficacy of direct-acting antiviral combination for patients with $\mathrm{HCV}$ genotype 1 infection and severe renal impairment or end-stage renal disease. Gastroenterology. 2016;150(7):1590-8. doi:10.1053/j.gastro.2016.02. 078.

68. Roth D, Nelson DR, Bruchfeld A, et al. Grazoprevir plus elbasvir in treatment-naive and treatment-experienced patients with hepatitis C virus genotype 1 infection and stage 4-5 chronic kidney disease (the C-SURFER study): a 
combination phase 3 study. Lancet. 2015;386(10003):1537-45.

69. Yeh WW, Caro L, Guo Z, et al. Pharmacokinetics of co-administered HCV protease inhibitor MK-5172 and NS5A inhibitor MK-8742 in volunteers with end-stage renal disease on hemodialysis or severe renal impairment not on hemodialysis. Hepatology. 2014;60(suppl 4):1940.

70. http://www.fda.gov/NewsEvents/Newsroom/Press Announcements/ucm483828.htm.

71. Saxena V, Koraishy FM, Sise ME, et al. Safety and efficacy of sofosbuvir-containing regimens in hepatitis $C$ infected patients with impaired renal function. Liver Int. 2016.

72. Nazario HE, Ndungu M, Modi AA. Sofosbuvir and simeprevir in hepatitis $C$ genotype 1-patients with end-stage renal disease on hemodialysis or GFR $<30 \mathrm{~mL} / \mathrm{min}$. Liver Int. 2016;36(6):798-801. doi:10.1111/liv.13025.

73. Singh T, Guirguis J, Anthony S, Rivas J, Hanouneh IA, Alkhouri N. Sofosbuvir based treatment is safe and effective in patients with chronic hepatitis $C$ infection and end-stage renal disease: a case series. Liver Int. 2016;36(6):802-806. doi:10.1111/liv. 13078.

74. Maruyama A, Partovi N, Yoshida EM, Erb SR, Azalgara VM, Hussaini T. A review of direct-acting antivirals for the treatment of hepatitis $\mathrm{C}$ in patients with advanced chronic kidney disease. Nephrol Dial Transplant. 2015. doi:10.1093/ndt/ gfv361

75. Kirby BJ, Symonds WT, Kearney BP, Mathias AA. Pharmacokinetic, pharmacodynamic, and drug-interaction profile of the hepatitis $C$ virus NS5B polymerase inhibitor sofosbuvir. Clin Pharmacokinet. 2015;54(7):677-90.

76. Martin P, Gane EJ, Ortiz-Lasanta G, et al. Safety and efficacy of treatment with daily sofosbuvir $400 \mathrm{mg}+$ ribavirin $200 \mathrm{mg}$ for 24 weeks in genotype 1 or $3 \mathrm{HCV}$-infected patients with severe renal impairment. Poster 1128, AASLD abstract Hepatology, vol 62, 1(suppl).

77. Saxena V, Nyberg L, Pauly M, et al. Safety and efficacy of simeprevir/sofosbuvir in hepatitis C-infected patients with compensated and decompensated cirrhosis. Hepatology. 2015;62(3):715-25.
78. Janssen, Inc (simeprevir) product monography, 2015 and Simion A, Mortier S, Peeters M, et al. Pharmacokinetics of Simeprevir (TMC435) in volunteers with severe renal impairment. In: 8th HEPCam workshop-clinical pharmacology, Cambridge, UK, 26-28 June 2013 http://regist2. virology-education.com/2013/8hepcam/docs/04_ simion.pdf.

79. Ledipasvir/Sofosbuvir (Harvoni ${ }^{\circledR}$ ) National Drug Monograph. VA Pharmacy Benefits Management Services, Medical Advisory Panel, VISN Pharmacist Executives and Office of Public Health. 2014. https://vaww.cmopnational.va.gov/cmop/PBM/de fault.aspx.

80. Garimella T, Wang R, Luo WL, et al. Single-dose pharmacokinetics and safety of daclatasvir in subjects with renal function impairment. Antivir Therapy. 2015;20(5):535-43.

81. AbbVie Corp. Hlkira PAK ombitasvir/paritaprevir/ ritonavir 12.5/75/50 $\mathrm{mg}$ and dasabuvir $250 \mathrm{mg}$, tablets product monograph, 2014.

82. Khatri A, Dutta S, Marbury $\mathrm{T}$, et al. The pharmacokinetics and safety of the direct acting antiviral regimen of ABT-450/r, ombitasvir with/ without dasabuvir in subjects with mild, moderate and severe renal impairment compared to subjects with normal renal function. In: 65th annual meeting of the American Association for the Study of Liver Diseases Boston, 2014.

83. Pockros PJ, et al. Ombitasvir-paritaprevir-ritonavir and dasabuvir in GT1 \& renal disease RUBY-I: 50th EASL. 2015; Abstract L01.

84. Yeh W, Caro L, Guo Z, et al. Pharmacokinetics of co-administered $\mathrm{HCV}$ protease inhibitor Grazoprevir (MK-5172) and NS5A Elbasvir (MK-8742) in volunteers with end-stage renal disease on hemodialysis or severe renal impairment not on hemodialysis. J Hepatol. 2014;60 Suppl 4:1940.

85. Roth D, Nelson DR, Bruchfeld A, et al. Grazoprevir plus elbasvir in treatment-naive and treatment-experienced patients with hepatitis C virus genotype 1 infection and stage 4-5 chronic kidney disease (the C-SURFER study): a combination phase 3 study. Lancet. 2015;386(10003):1537-45. 